I Pontifícia Universidade Católica do Rio de Janeiro

..(PUC-Rio), RJ, Brasil

Pesquisadora convidada

livia.barbosa3@gmail.com

https://orcid.org/0000-0003-3674-62 I0

Livia Barbosa'

\title{
DANIEL MILLER E OS ESTUDOS DE CONSUMO NO BRASIL
}

Em 2002 convidou-me a editora responsável pela publicação no Brasil do livro Teoria das compras, de Daniel Miller, para escrever a apresentação da obra, que eu mesma havia sugerido no contexto de uma coleção multidisciplinar sobre consumo e sociedade de consumo. Como pesquisadora do tema, eu tinha apresentado uma lista ambiciosa de títulos clássicos, entre os quais constava, também, Material culture and mass consumption, a partir de agora referido como MCMC, objeto de nossas homenagens pelos 33 anos de publicação.

Teoria das compras foi publicado com o subtítulo $O$ que orienta as escolhas dos consumidores, talvez como expectativa dos editores de que com isso pudessem atrair gama maior de interessados e atenuar o peso acadêmico da obra. A apresentação do livro começava com a frase "Daniel Miller não é um autor conhecido no meio acadêmico brasileiro" (Barbosa, 2002: I I), afirmação que se viu desmentida ao longo destes últimos 18 anos no âmbito dos estudos de consumo no Brasil, cuja própria constituição, embora ocorra de forma independente, tem nos trabalhos de Daniel Miller uma de suas principais inspirações teóricas.

MCMC, entretanto, não foi traduzido, como a maioria dos demais livros recomendados, e a coleção, inicialmente programada para mais de dez títulos, se encerrou. Refletir sobre a obra teórica inicial de Daniel Miller e sua importância no âmbito dos novos estudos de consumo, a partir de agora referido como NEC, se faz, portanto, fundamental pelas contribuições que ela aporta a esse campo. 
Em primeiro lugar, MCMC propõe uma teoria geral do consumo, destacando o papel-chave que este possui na modernidade. Em segundo, a partir do esquema filosófico de Hegel, especificamente do processo de desenvolvimento do sujeito, Miller sugere uma nova leitura do conceito de objetificação, no contexto da qual o consumo surge como um mecanismo de transformação de artefatos alienáveis em cultura inalienável. Em terceiro, o consumidor é reinvestido de um papel ativo na "ressocialização" de bens e mercadorias em cultura inalienável. E, por fim, Miller sugere uma reflexão alternativa acerca da natureza contraditória da sociedade contemporânea ao assumir que os bens de massa são a nossa cultura. E o são, como muito bem destaca Duarte (2010: 377), porque não só "fazem parte do meio ambiente em que operamos, mas também porque são uma parte integrante do processo de objetificação pelo qual nos criamos a nós próprios como sociedade industrial".

\section{MATERIAL CULTURE E MASS CONSUMPTION}

MCMC, de Daniel Miller, foi publicado em I987 ao final de mais de duas décadas de inúmeras e significativas publicações que inspiraram uma nova abordagem ao estudo do consumo e das relações da sociedade contemporânea com a materialidade. Abordagem essa que veio se contrapor a várias décadas de interesse acadêmico e teorização social centrados na esfera da produção paralelamente ao tratamento do consumo como mero reflexo da anterior.

Grant McCracken (I987) ao fazer uma revisão crítica daquelas duas décadas sugere, ironicamente, que se ela fosse uma economia em desenvolvimento corresponderia à etapa do take off do economista W.W. Rostow (I953). Levando essa analogia para os estudos do consumo equivaleria dizer que naquele momento teria ocorrido o rompimento das resistências contra novos olhares analíticos seguido do estabelecimento de uma nova "dinâmica produtiva" em termos teóricos. Esse período de take off é considerado pelos pesquisadores um divisor de águas, para o qual a maioria das disciplinas acadêmicas de ciências sociais deu sua contribuição aos NEC (NCS, acrônimo em inglês). ${ }^{\text {I Dentre as }}$ teses mais expressivas desse momento de take off as desenvolvidas por Daniel Miller em MCMC se destacam por configurar uma instigante reflexão sobre as nossas relações com a cultura material e sobre nós mesmos enquanto antropólogos, acadêmicos e membros de uma sociedade de consumo de massa.

Relegada ao sótão das reflexões das ciências sociais por mais de 40 anos no século $\mathrm{XX}$, a preocupação com a abundância material e seu consumo na sociedade contemporânea constituíram um objetivo frívolo e alienado para grande parte do mundo acadêmico e intelectual. Segundo Miller (I987), essa percepção da cultura material contemporânea como uma forma inferior de autenticidade primitiva, caso da antropologia clássica, ou como a expressão alienada/alienante de um capitalismo opressivo que separa o criador da sua obra, caso marxista, ou ainda como o resultado de uma era obcecada com a 
aparência em detrimento da essência, "consumida" por um tipo de doença cultural marcada pela superficialidade e insatisfação permanentes, caso dos frankfurtianos e afins, tem profundas raízes no pensamento filosófico ocidental (Woodward, 2007). O contraponto a essa "ausência de tudo" nos termos dessa crítica - autenticidade, profundidade existencial, criatividade, capacidade de distinguir entre qualidade e mediocridade - encontrar-se-ia em expressões culturais autênticas e em seu consumo adequado, como ópera, literatura e belas artes, em sociedades não mais governadas pelo materialismo capitalista.

Assim, quando Miller retoma a questão da cultura material na década de 1980 e faz dela o objeto teórico central de seu livro, ele está recolocando um conceito que fora deslocado para a periferia dos temas acadêmicos no centro das considerações teóricas das ciências sociais como instrumento fundamental para o entendimento da sociedade e da cultura de massa. Ele se propõe a interrogar o que acontece quando nos defrontamos com a materialidade abundante que nos circunda; como e de que maneira extraímos significados dos objetos/mercadorias com os quais nos relacionamos; e se o consumo aguça ou resolve as contradições da sociedade contemporânea.

De acordo com Miller, em vez de nos concentrar no que a cultura de consumo e suas instituições (indústria cultural, marketing, propaganda etc.) tentam nos impingir - superficialidade, homogeneidade, insaciabilidade - ou no que ela é acusada de nos privar - autenticidade, realização pessoal, integridade existencial etc. - deveríamos nos voltar para o que a sociedade de consumo nos permite ser, fazer, sentir e pensar a partir de nossas relações com a cultura material e o consumo de massa na contemporaneidade. Segundo o autor, o consumo não é um refúgio para a "alienação contemporânea", como enfatizado negativamente por diferentes autores (Adorno \& Hokheimer, I 985; Bauman, 200I). Ao contrário, é o mecanismo pelo qual os atores sociais empreendem o esforço cotidiano de extrair sua própria humanidade. É um ato potencialmente criativo, que consiste "na transformação de um objeto alienável para a condição de objeto inalienável, investido de conotações específicas" (Miller, I987: I90).

Essas conotações específicas começam a ser atribuídas à mercadoria no momento de sua aquisição, seja por intermédio do mercado ou do Estado, quando a natureza única de uma pessoa é expressa na escolha de um item em particular e/ou na reconfiguração de algum outro. A esse momento inicial seguese um processo ao longo do qual o agente social age/trabalha sobre o artefato até o ponto de ele não ser mais reconhecível como tendo qualquer relação com o mundo abstrato e impessoal de onde veio.

Em outros termos, quando as mercadorias emergem do universo produtivo elas constituem conjuntos de potencialidades materiais e simbólicas inespecíficas à espera de ser realizadas. Por outro lado, quando adquiridas/recebidas, essas mercadorias são apropriadas e "ressocializadas" no contexto de 
universos particulares individuais e/ou coletivos. O objeto é transformado a partir de sua associação íntima com um indivíduo e/ou grupo social particular e das relações entre eles (Miller, I987: I9I).

Essas transformações a que Miller se refere são diversas. Envolvem tanto aquelas a que o artefato é submetido ao longo de sua existência física quanto sua participação/construção em um ambiente cultural específico. Valendo-se da quantidade de trabalho dos agentes sociais contida em um pint of beer, Miller ilustra o que afirmou teoricamente. Em sua opinião, todas as práticas culturais que constituem a cultura do pub (a compra de rounds, a escolha da marca de cerveja, a rede de sociabilidade etc.) e que faz do pint o que ele é no contexto inglês não podem ser reduzidas apenas a processos de distinção social, como se poderia argumentar a partir de Bourdieu. Essas práticas configuram uma presença material importante, geradora de sociabilidade, de ideias de moralidade e de outros tipos de abstrações e princípios (Miller,ı987: I9I). Claro que essa não é uma descrição de todo consumo ou o objetivo consciente de todos os participantes, como enfatiza Miller. O fundamental, contudo, é que é imanente ao consumo.

Se o consumo tem essa potencialidade, a sociedade de consumo e sua abundante cultura material não representariam, necessariamente, nossa condenação. Ao contrário, a cultura material seria a nossa possibilidade de redenção, pois por seu intermédio resgataríamos nossa humanidade. Diagnóstico oposto ao de grande parte dos teóricos que dela trataram, a começar pelo próprio Marx. Qual é, porém, a estrutura teórica que sustenta essa interpretação do consumo que Miller nos oferece em MCMC? É o conceito de objetificação de Hegel.

Segundo Hegel a objetificação se constitui em um processo dual, pelo qual o sujeito em um primeiro momento se autoexternaliza a partir de um ato criativo de diferenciação para em seguida dele se reapropriar. Embora ocorra a separação entre o sujeito e sua criação, não existem nem a perda nem a eliminação desta última, mas um novo movimento, igual ao anterior. Esse jogo dialético, progressivo, encontra seu término não por uma externalização/reapropriação última/definitiva, mas quando o sujeito se torna capaz de visualizar toda a trajetória percorrida nesse processo (Miller, I987; Rosales, 2009; Duarte, 20I0).

Em Marx, a noção de objetificação é formulada também através de um processo dual entre o sujeito e sua externalização no mundo, mas o resultado é negativo no que concerne à sociedade capitalista. Segundo Marx, a natureza humana se realiza através do trabalho produtivo. É a posse do resultado material desse processo criativo que garante ao sujeito a sua possibilidade de autoconsciência e o estabelecimento de relações sociais autênticas. Contudo, na sociedade capitalista de produção em massa o sujeito é expropriado do resultado do seu trabalho, da sua criação. Os objetos ganham existência própria integrando uma esfera exterior aos indivíduos para além do seu controle, que perfazem o mundo das mercadorias. Assim, alienados do fruto do seu trabalho, 
os sujeitos se voltam para o consumo como fonte de gratificação "inautêntica" ou o transformam em um "cenário" a partir do qual "estabelecem, reforçam e recriam novas formas de relação e estratificação social" baseadas em uma materialidade fetichizada (Rosales, 2009).

Se a partir de Marx nos habituamos a pensar a mercadoria como o resultado de estruturas opressivas e abstratas, com Miller começamos a vê-la como a sua própria negação. Essa "luta permanente" para nos apropriarmos de bens e serviços, não promove a ruptura entre o resultado da atividade criativa e o seu criador, fonte de toda a alienação. Por conseguinte, não se torna um entrave à realização humana. Focar nos aspectos materiais da existência, nas relações que estabelecemos com as coisas que nos cercam, não significa tornarmo-nos superficiais, inautênticos e vazios, como alerta Miller (I987). As coisas, os bens e serviços e a materialidade da qual são feitos não constituem uma superestrutura distanciada em relação ao mundo social no qual vivemos. Ao contrário, eles se constituem nas projeções externas da sociedade contemporânea industrial, que através do seu consumo reincorpora as suas próprias externalizações, refundindo-as em cultura inalienável.

A teoria geral do consumo que Miller nos apresenta em MCMC (I987) é retomada e exemplificada em diferentes publicações posteriores tendo como base etnografias específicas. Por exemplo, em texto de I988, o autor mapeia todo o processo de "humanização" que os moradores de um conjunto habitacional de "moradias sociais", fornecidas pelo Estado, no norte de Londres, realizam em suas casas como forma de as tornar "suas/deles". Focalizando as reformas que os diferentes inquilinos fizeram em suas cozinhas, Miller (I988) sugere não existir nenhuma relação entre esses procedimentos e a renda dos moradores. As reformas encontram-se antes relacionadas ao tipo de vida social e sociabilidade dos inquilinos e com sua tentativa de neutralizar a dimensão impessoal e institucional dessas "moradias sociais", transformando-as em universos particulares que expressam a natureza singular de seus habitantes. Em Teoria das compras, Miller (I998a) nos mostra como a atividade cotidiana de aquisição de alimentos traz à tona significativos aspectos normativos e morais da modernidade, como um éthos de comedimento e sacrifício, justamente o contrário do discurso abstrato sobre compras em geral, que enfatiza autoindulgência, extravagância, excesso e impulsividade e seria característico da contemporaneidade (Bauman, /200I). No decorrer de uma aprofundada etnografia Miller (I 998a) constata que a maioria das compras não é realizada em função das pessoas que as fazem, mas tem como referência pais, filhos e demais "objetos devocionais", que necessariamente não se encontram presentes, mas que são os "nortes" de quem as concretiza. Por isso o título do capítulo inicial é Making love in supermarkets (Miller, I998a: I5). A dinâmica de proporcionar prazer de forma escalonada a cada um dos "referentes ausentes" para manter o orçamento sob controle - o steak para o marido, a sobremesa para filha, o 
refrigerante para o filho, mas nunca todos os desejos de todos - encontra-se sublinhada por um éthos de comedimento que ao gastar se economiza. Como sugere Miller, a compra transforma despesas num ritual de devoção para com aqueles que amamos, e envolve "trabalho" sob a forma de dedicação e esforço, mas de forma alguma passividade por parte de quem a realiza. Daí Miller associá-la ao ritual do sacrifício e a suas diferentes etapas: excesso/despesas, sacrifício/transformação de despesa em comedimento e transcendência/compra como expressão geral de afeto e cuidado.

Várias outros livros como A theory of virtualism (Miller, I998b), Material cultures (Miller, I998c), The comfort of things (Miller, 2008), Stuff (Miller, 2010), tanto os de autoria individual como os produzidos com colaboradores, têm a interligá-los justamente o movimento pendular entre abstração/reapropriação realizado por sujeitos humanos específicos mergulhados em universos materiais concretos. Conceitos que existem como potencialidades materiais inespecíficas, tais como roupas, casa, plataformas digitais como Facebook, são particularizados a partir de seus efeitos reais na maneira como uma mulher indiana usa o sari, e uma inglesa o jeans, ou como os posts ingleses no Facebook são distintos daqueles dos trinadianos. E ilustram com clareza as complexidades de nossas relações com os bens materiais e como nos construímos e somos construídos pela materialidade.

Para Miller (I998a, I998b, I998c, 20Io), contudo, a continuidade de seu projeto teórico não se resume apenas a enfatizar a importância da materialidade em nossas vidas, nem o consumo como lócus potencial de extração/produção de nossa humanidade e/ou, menos ainda, a tratar os objetos como uma linguagem. Ele acredita que isso já foi demonstrado. A tarefa à frente é desvendar como e por que as coisas importam em contextos específicos. Daí o uso da palavra matter, que, como o próprio autor salienta, tem uma conotação mais emocional do que outros termos assemelhados e refletiria melhor as particularidades daquele para quem ela importa (Miller, I998). Tarefa essa que só pode ser realizada pelo exercício etnográfico aprofundado, a força fundamental a guiar Miller ao longo de toda a sua trajetória.

A etnografia para Miller é o instrumento metodológico ímpar capaz de desafiar formas tradicionais e cristalizadas de ver a realidade e, por conseguinte, de produzir conhecimento relevante sobre o mundo a partir de novos olhares. Por isso ele enfatiza a necessidade de a antropologia "não ser ideológica", ou seja tratar todas as sociedades como iguais, não romantizar o "primitivo" e/ou "fetichizar" o contemporâneo. Ambos são merecedores de atitude respeitosa e empática.

No processo etnográfico, a observação dos sujeitos nas suas condições reais de existência ocupa, segundo Miller, um lugar privilegiado. Ao observar o que as pessoas fazem, podemos perceber que outras coisas são relevantes além daquilo que elas afirmam que fazem e dizem considerar importante. Coisas que muitas vezes os sujeitos não reconhecem ou não percebem, mas que podem ser captadas 
em suas ações e seus discursos pelas ambiguidades, justificativas e negações que invocam. Essa ênfase na observação não significa ignorar as entrevistas ou o falar com os informantes. Significa não transformar a etnografia em apenas entrevista e questioná-la permanentemente a partir dos atos e contextos dos sujeitos que a produzem.

Como Miller (I987: 8) já constatara em MCMC, as pessoas desenvolvem inúmeras estratégias para transformar os recursos materiais que possuem, sejam esses oriundos do mercado ou do Estado, em "ambientes expressivos, rotinas diárias e frequentemente ideais cosmológicos". De acordo com o autor, o comportamento humano em relação às coisas materiais, quando inserido em contextos socioculturais mais amplos, constitui-se, do ponto de vista etnográfico, na maior evidência a ser registrada e interpretada.

\section{DANIEL MILLER E OS ESTUDOS DO CONSUMO NO BRASIL}

No Brasil, os NEC começaram a surgir no final dos anos I 990 e início do século XXI, com quase 20 anos de defasagem com relação à Europa e aos Estados Unidos. ${ }^{2}$ Esse período é marcado pela tradução de alguns trabalhos importantes, tais como os de Colin Campbell (I987), Daniel Miller (I998) e Don Slater (I997) em 2002, Grant MacCracken (I988) em 2003, seguidos um pouco mais tarde pelos de Mary Douglas e Baron Isherwood (I979) em 2004, de Pierre Bourdieu (I979) em 2007 e de Arjun Appadurai, (I 986) em 2008, embora a maior parte das publicações clássicas daquele período jamais tenha sido traduzida para o português.

Um dos elementos-chave para essas traduções foi a participação de alguns desses autores em eventos acadêmicos organizados no Brasil por pesquisadores interessados nos NEC, no início do século XXI; 3 outro, a simultânea presença de estudantes brasileiros em centros europeus, trabalhando em programas de qualificação acadêmica com alguns desses pesquisadores, dentre os quais Miller se destaca (Barbosa \& Wilkinson, 2017).

Essa constatação levanta questões sociologicamente interessantes acerca da genealogia das traduções de determinados livros e autores para outros universos acadêmicos e culturais. Como é possível observar, a sequência das traduções brasileiras citadas não obedece ao aparecimento desses trabalhos tanto na Europa como nos Estados Unidos. Algumas apresentam atraso de mais de 20 anos em relação à data da publicação original. Mais interessante ainda é o fato de que sua ausência não significa que os autores não fossem conhecidos e lidos no Brasil, como nos casos de Mary Douglas, Pierre Bourdieu e Arjun Appadurai - embora citados pelos cientistas sociais brasileiros anteriormente a esse período, os três eram lidos e integrados em contextos não diretamente relacionados aos NEC, como vieram a ser posteriormente (Barbosa \& Wilkinson, 2017). ${ }^{4}$

Do ponto de vista institucional, foi também depois de 2000 que cientistas sociais brasileiros começaram a organizar cursos e seminários sobre esse tema. Em levantamento realizado por Portilho e Galindo (20I 2) em 250 trabalhos 
apresentados, entre I980 e 2009, à SBS e à ANPOCS, selecionados a partir da palavra "consumo" no título ou nas palavras-chave, 236 o foram depois de 2004. A partir de 2002, livros, dissertações e teses da área de ciências sociais, principalmente de antropologia e comunicação, começam a ser publicados e escritos tendo o consumo como tema ou palavra-chave. Embora essas publicações e pesquisas cubram áreas variadas de interesses, como alimentação, vestuário, moradia, consumo cultural, entre outras (Alcoforado, 2007; Barros, 2007; Goidanich, 20I2; Gonçalves, 20I4; Bueno \& Camargo, 2008; Barbosa \& Campbell, 2006; Rial et al., 20I2; Silva, 2010), e disciplinas como antropologia, comunicação e marketing (Leitão et al., 2006; Migueles, 2007; Bueno \& Camargo; 2008, Baccega, 2008; Oliven \& Pinheiro-Machado, 2007), duas áreas merecem menção especial: os estudos das chamadas novas classes médias e o das novas mídias sociais. Ambas vão ter nos trabalhos de Daniel Miller sobre a cultura material e a antropologia digital importante interlocução.

Independentemente das inúmeras críticas acerca da expressão "novas classes médias", do uso político/ideológico das políticas de transferência de renda e das limitações contidas no entendimento do consumo como cidadania (Souza, 20Io), esse período de efervescência econômica e "consumismo" teve duas implicações importantes para os estudos de consumo. Por um lado chamou a atenção do Brasil para os brasileiros como uma sociedade de consumo, rompendo as tradições de análise acadêmica vigentes, nas quais a sociedade brasileira e particularmente os segmentos na base da pirâmide eram definidos por suas faltas, carências ou presenças "negativas" (Barbosa \& Campbell, 2006; Barbosa \& Wilkinson, 20I7). Por outro, despertou o interesse dos pesquisadores acerca dos padrões, das práticas e das experiências de consumo associadas a esses segmentos, (Barros, 2007; Mattoso, 2005; Rocha \& Silva, 2009; Yaccoub, 20I5; Barros, 20I5; Torquato, 2013).

A nova cultura material a que eles passaram a ter acesso - produtos alimentares diferenciados, linha branca nova, eletroeletrônicos de última geração, carros populares e viagens de avião - oportunizou, do ponto de vista etnográfico, contextos e situações para expressões de ideais, moralidades, gostos, estilos e anseios testemunhas de suas existências para além da carência material de suas vidas, que até então os mantinham invisíveis para o resto da sociedade. Nesse contexto, o consumo como a reapropriação de bens alienáveis em cultura inalienável e resgate da humanidade de cada um de nós, como proposto por Miller, encontrou terreno fértil .

As mídias sociais digitais compõem outro tema de investigação em que os estudos de consumo no Brasil vêm marcando presença desde o final da década passada, e a influência das pesquisas de Miller nessa área se faz claramente presente (Miller \& Slater, 2000; Miller, 20I I; 20I6). A proposta de uma antropologia digital visa explorar o vínculo entre as relações socioculturais e os usos e práticas a que os usuários de diferentes plataformas, dispositivos e 
aplicativos digitais as submetem inter e intrassociedades. Nesse contexto - em cujo interior novos conceitos estão sendo articulados, como o de polymedia, humanidades digitais, sociabilidades mensuráveis etc. -, o jogo entre objetificação/reapropriação central em MCMC pode ser relido nas oposições universalismo/particularismo e/ou global/local, que nos permitem acompanhar o modo como as diferentes sociedades metabolizam os dispositivos tecnológicos atuais, reproduzindo lógicas e significados já existentes ao mesmo tempo em que outros são criados (Rial, 20I2; Silva, 20Io; Machado, 20I5, 20I8).

Ao final desta segunda década os estudos de consumo no Brasil apresentam-se diversificados tanto em temas como em orientação teórica, com a inclusão de autores e teorias relacionados aos NEC. Em levantamentos preliminares feitos por Barbosa e Soares (20I5) no banco de teses da Capes e nas bibliografias utilizadas em I3 livros sobre consumo, editados por pesquisadores de vários cursos de graduação, localizados em diferentes áreas geográficas do Brasil, publicados entre 2006 e 20 I5, envolvendo I83 autores, quando se computou a frequência de citação dos diferentes autores, constataram-se três aspectos principais. Primeiro, linhas de pesquisa inspiradas pelos NEC, principalmente as que focalizam nossas relações com a materialidade como aspecto constitutivo da vida social, podem ser identificadas e trazem um frescor interpretativo. Nessas, Daniel Miller é um dos autores mais citados. Segundo, temas que agora aparecem sob o rótulo de consumo, cultura material ou ambos, entre outros, não teriam sido assim classificados há cerca de I5 ou 20 anos. Terceiro, estudos relacionados a produtos culturais, comunicação, mídia (com exceção das mídias digitais), cultura e sociedade de consumo são predominantemente abordados a partir de uma orientação marxista, frankfurtiana e/ou pós-moderna, utilizando-se material empírico como textos ou discursos por uma abordagem predominantemente semiológica.

A partir de 20io, um novo conjunto de temas se faz presente, trazido pelo crescimento dos novos movimentos sociais, particularmente os associados a identidades coletivas, que transformaram o consumo em um espaço no qual direitos podem ser reivindicados, legitimados e/ou contestados, e formas alternativas de consumo como instrumentos de transformação política e expressão de comportamento ético começam a ser articuladas. Esse é o caso do meio ambiente, dos direitos dos animais, da vinculação entre feminismo e vegetarianismo/veganismo entre outros. Muitas das críticas elaboradas em MCMC e nos trabalhos posteriores de Daniel Miller poderão ganhar novas dimensões e pertinência analítica. Mas, certamente esses novos temas e significados fornecem oportunidade ímpar para mapear as reapropriações específicas que subjazem a essas abstrações globais, de forma a resgatar as múltiplas formas pelas quais construímos nossas respectivas "humanidades". 


\section{NOTAS}

I Acknowledging consumption: a review of new studies (Miller, I995) reúne um conjunto das mais significativas contribuições daquele momento.

2 Isso não significa que antes desse período o consumo não tivesse sido objeto de atenção acadêmica no Brasil. Ao contrário, uma revisão histórica do tema pode ser encontrada em Barbosa e Wilkinson (2017)

3 Dentre esses eventos destaca-se o Enec que em suas nove edições até o momento e 18 anos de existência trouxe ao Brasil os seguintes pesquisadores da área de consumo, alguns, aliás, mais de uma vez: Colin Campbell, Frank Cochoy, Daniel Miller, Alan Warde, Gary Cross, Geert Spaargaren, Michele Micheletti, Frank Trentman, Philippe Steiner e Ken Albala. Richard Wilks participou como palestrante em uma das edições por videoconferência.

4 Para questão semelhante ver Incômodos best sellers, de José Carlos Durand (20I5), que analisa a maneira como alguns clássicos da publicidade nos Estados Unidos foram traduzidos, lidos e interpretados no Brasil.

Livia Barbosa é doutora em antropologia social pelo PPGAS/UFRJ, mestre em ciências sociais pela Universidade de Chicago e tem estudos de pós-doutorado na Universidade de Tokyo e no PPGAS/ UFRJ. É professora da Universidade Federal Fluminense e pesquisadora convidada da Pontifícia Universidade Católica do Rio de Janeiro. É autora de vários livros e artigos, dentre os quais se destacam $O$ jeitinho brasileiro ou a arte de ser mais igual que os outros; 


\section{REFERÊNCIAS BIBLIOGRÁFICAS}

Adorno, Theodor \& Horkheimer, Max. (I985) [1944]. Dialética do esclarecimento. Rio de Janeiro: Editora Zahar.

Alcoforado, Flavio. (2007). A escolha de planos de saúde pelo consumidor: uma visão antropológica. In: Migueles, Carmen (org.). Antropologia do consumo. Rio de Janeiro: Editora da FGV.

Appadurai, Arjun. (1986). The social life of things. Cambridge: Cambridge University Press.

Bacega, Maria Aparecida. (2008). Comunicação e culturas do consumo. São Paulo: Editora Atlas.

Barbosa, Livia.(2006a). Apresentação. In: Barbosa, Livia e Campbell, Colin. Cultura, consumo e identidade. Rio de Janeiro: Editora da FGV.

Barbosa, Livia(2006b). O consumo nas ciências sociais. In: Barbosa, Livia \& Campbell, Colin. Cultura, consumo e identidade. Rio de Janeiro: Editora da FGV.

Barbosa, Livia. (2002). Apresentação. In: Miller, Daniel. Teoria das compras. São Paulo: Nobel.

Barbosa, Livia \& Campbell, Colin. (2006). Cultura consumo e identidade. Rio de Janeiro: Editora da FGV.

Barbosa, Livia \& Soares, Cecília. (2015). Levantamento sobre a produção acadêmica em torno do tema consumo. Rio de Janeiro. Não publicado.

Barbosa, Livia \& Wilkinson, J. (2017) Consumption in Brazil - the field of new consumer studies and the phenomenon of the new middle classes. In: Keller, Margit et al. The handbook on consumption. London/New York: Routledge. Barros, Carla. (2007). Hierarquia, escassez e abundância materiais: um estudo etnográfico no universo de consumo das empregadas domésticas. In: Migueles, Carmen (org.). Antropologia do consumo. Rio de Janeiro: Editora da FGV.

Barros, Denise Franca. (2015). Consumo consciente e a "nova classe média brasileira": uma investigação inicial. In: Borges, Silvia et al. (orgs.). Consumo e sociabilidades. Espaços, significados e reflexões. Rio de Janeiro: e-papers. Bauman, Zygmunt. (200I). Consuming life. London: Sage Publications. 
Bourdieu, Pierre. (2007). A distinção. Crítica social do julgamento. São Paulo: Edusp.

Bueno, Maria Lucia \& Camargo, Luiz Octavio. (2008). Cultura e estilos de vida na contemporaneidade. São Paulo: Editora Senac.

Campbell, Colin. (1987). The romantic ethics and the spirit of modern consumerism. Oxford: Basil Blackwell.

Douglas, Mary \& Isherwood, Baron. (2004). O mundo dos bens. Para uma antropologia do consumo. Rio de Janeiro: Editora UFRJ.

Duarte, Alice. (2010). A antropologia e o estudo do consumo: revisão crítica das suas relações e possibilidades. Etnográfica, I4/2, p. 363-393.

Durand, José Carlos. (20I5). Incômodos best sellers, USA. Publicidade, consumo e seus descontentes. São Paulo: Edusp.

Goidanich, Maria Elizabeth. (2012). Mamãe vai ao supermercado. Uma abordagem etnográfica das compras para o cotidiano. Tese de Doutorado. PPGCH/Universidade Federal de Santa Catarina. 249p.

Gonçalves, Patricia Rocha. (20I4). Cardápio do dia. Consumo alimentar entre os jovens da nova classe média. Tese de Doutorado. CPDA/Universidade Federal Rural do Rio de Janeiro. ı6op.

Leitão, Débora Krischke et al. (2006). Antropologia e consumo. Diálogos entre Brasil e Argentina. Porto Alegre: Editora Age. Machado, Monica. (2018) A teoria da antropologia digital para as humanidades digitais. Revista Z Cultural, I2/2, p. 20-35.

Machado, Monica. (2015). Polymedia e culturas juvenis: estudo de caso em uma favela carioca. Revista Z Cultural, Io/I, p. 50-65.

Mattoso, Cecília Lima de Queirós. (2005). Me empresta o seu nome? Um estudo sobre os consumidores pobres e seus problemas financeiros. Rio de Janeiro: Mauad X.

McCracken, Grant. (1988). Culture and consumption. New approaches to the symbolic character of consumer goods and activities. Bloomington: Indiana University Press.

McCracken, Grant. (1987). Describing the consumer society: the problem of pleasure. The Semiotic Review of Books, I/I. 
Migueles, Carmen (org.). (2007). Antropologia do consumo. Casos brasileiros. Rio de Janeiro: Editora da FGV.

Miller, Daniel. (2016). How the world changed social media. London: UCL Press.

Miller, Daniel. (20II). Tales from Facebook. Cambridge: Polity.

Miller, Daniel. (20I0). Stuff. Cambridge: Polity.

Miller, Daniel. (2008). The comfort of things. Cambridge: Polity.

Miller, Daniel. (I998a). A theory of shopping. New York: Cornell University Press.

Miller, Daniel. (I998b). Conclusion: a theory of virtualism. In: Carrier, James \& Miller, Daniel. Virtualism. A new political economy. Oxford: Berg.

Miller, Daniel. (I998c). Material cultures. Why some things matter. Chicago: Chicago University Press.

Miller, Daniel (ed.). (1995). Acknowledging consumption. A review of new studies. London/New York: Routledge.

Miller, Daniel. (I988). Appropriating the state on the council estate. Man, 23, p. 353-372.

Miller, Daniel. (1987). Material culture and mass consumption. Cambridge: Basil Blackwell.

Miller, Daniel \& Slater, Don. (2000). The internet. An ethnographic approach. Oxford: Berg.

Oliven, Ruben \& Pinheiro-Machado, Rosana. (2007). Antropologia e consumo. Horizontes Antropológicos, I3/28.

Portilho, Fátima \& Galindo, Flávia. (2012). Estudos de consumo no Brasil. A construção de um novo campo nas ciências sociais brasileiras. VI Encontro Nacional de Estudos do Consumo. Rio de Janeiro.

Rial, Carmen et al. (2012) Consumo e cultura material: perspectivas etnográficas. Florianópolis, Ed. da UFSC.

Rocha, Angela \& Silva, Jorge Ferreira (orgs.). (2009). Consumo na base da pirâmide. Rio de Janeiro: Maud X.

Rosales, Marta Vilar. (2009). Cultura material e consumo. Lisboa: Celta Editora.

Rostow, Walter Whtiman. (I953). Etapas do desenvolvimento econômico. Um manifesto não comunista. Rio de Janeiro: Zahar Editores. 
Slater, Don. (1997). Consumer culture and modernity. Cambridge: Polity Press.

Silva, Sandra Rúbia. (2010). Estar no tempo, estar no mundo: a vida social dos telefones celulares em um grupo popular. Tese de Doutorado. PPGAS/Universidade Federal de Santa Catarina.

Souza, Jesse. (2010). Os batalhadores brasileiros: nova classe média ou nova classe trabalhadora? Belo Horizonte: UFMG.

Torquato, Shirley. (2013). Casa nova, vida nova: consumo, despesas e orçamento entre moradores do PAC do Morro do Preventório. Tese de Doutorado. PPGAS/Universidade Federal Fluminense. 290p.

Woodward, Ian. (2007). Understanding material culture. London: Sage.

Yaccoub, Elaine (org.). (20I5). Consumo popular. Rio de Janeiro: Mundo do Marketing Editora. 
Palavras-chave

Cultura material;

novos estudos de

consumo;

sociedade de consumo;

antropologia do

consumo;

antropologia digital.

Keywords

Material culture;

new consumer studies;

consumer society;

anthropology of consumption;

digital anthropology.

\section{DANIEL MILLER E OS ESTUDOS DE CONSUMO NO BRASIL}

\section{Resumo}

O texto tem como primeiro objetivo rever as propostas teóricas desenvolvidas por Daniel Miller acerca do significado da cultura material no contexto das produções acadêmicas das ciências sociais em seu hoje clássico Material culture and mass consumption. Nesse livro Miller não só propõe uma teoria geral do consumo como apresenta uma releitura do processo de objetificação, como desenvolvido por Hegel, e a partir desse oferece nova leitura para as contradições da sociedade contemporânea. Em um segundo momento, as ideias desenvolvidas pelo autor naquela oportunidade são examinadas em seu entrelaçamento com suas produções e pesquisas posteriores simultaneamente a sua influência teórica em alguns dos temas dos estudos de antropologia e consumo no Brasil, sobressaindo-se os realizados sobre consumo entre os segmentos na base da pirâmide social e os de antropologia digital.

\section{DANIEL MILLER AND STUDIES OF CONSUMPTION IN BRAZIL}

Abstract

This article examines the significance of the theoretical ideas developed by Daniel Miller on material culture in the broader context of the social sciences in his classic book Material Culture and Mass Consumption. In this book, Miller not only proposes a general theory of consumption but also presents a new reading of the process of objectification as developed by Hegel and on this basis offers a new interpretation of the contradictions of contemporary society. The ideas developed in this book are then analyzed in the light of his later publications, and finally we discuss the influence Miller's ideas on anthropology and consumption studies in Brazil, particularly those dealing with social groups at the base of the pyramid and digital anthropology. 